\title{
Humanistyka: pracownia, centrum czy laboratorium?
}

Urszula Pawlicka

TEKSTY DRUGIE 2017, NR 1, S. 314-333

DOI: 10.18318/td.2017.1.26

Dodobno nie wchodzi się dwa razy do tej samej rzeki. Humanistyka właśnie podejmuje to ryzyko, opuszczając pracownię na rzecz laboratorium. Już raz w swej historii „była” w laboratorium, które opuszczała z wielkim hukiem, gdyż okazało się, że „bycie” w laboratorium oznacza utratę samodzielności i własnej tożsamości. Wyjście z owego miejsca określa się przełomem antypozytywistycznym (XIX/XX wiek) - czas, kiedy humanistyka odłączyła się od nauk przyrodniczych, by uzyskać status pełnoprawnej dyscypliny i by zbudować fundamenty naukowe. W XXI wieku humanistyka powraca do laboratorium: świadomie, taktycznie i z wielkim rozmachem. Można by zatem powiedzieć, że to nie tyle "powrót", ile „przejęcie” pewnego modelu instytucjonalnego i dostosowanie go do warunków humanistycznych. Laboratorium nie kojarzy się już wyłącznie z pewną sferą nauk (przyrodniczych czy ścisłych), ale pociąga za sobą szereg pojęć determinujących fundamenty danej dyscypliny naukowej, takie jak współpraca i komunikacja badaczy, różnorodne inskrypcje oraz różnego rodzaju

\author{
Urszula Pawlicka - \\ dr, postdoctoral \\ researcher w Media \\ Lab Helsinki na Aalto \\ University w Finlandii. \\ Stypendystka na \\ Washington State \\ University Vancouver, \\ US (Fulbright Award \\ 2014/2015) oraz \\ na Stony Brook \\ University w Nowym \\ Jorku (2015). Publi- \\ kowała w pismach \\ naukowych. Ostatnia \\ publikacja w druku: \\ Literatura cyfrowa. \\ Wstronę podejścia \\ procesualnego (2017). \\ Kontakt: ulapawlic- \\ ka@gmail.com.
}


materialne artefakty' ${ }^{1}$ Miejsce implikuje zatem następujące zmiany: instytucjonalne, funkcjonalne, kognitywne i metodologiczne. Wejście humanistyki do laboratorium nie jest kaprysem, ale politycznym gestem i strategią instytucjonalną.

Konsekwencje przekroczenia progu laboratorium są ogromne, wiążą się bowiem z modyfikacjami w procesach i metodach prowadzenia badań naukowych. Laboratorium doprowadza do następujących przesunięć w badaniach humanistycznych: od opisu do produkcji, od metody do narzędzi, od tekstu do artefaktu oraz od teorii do praktyki. Laboratorium przeorientowuje dotychczasowe założenia humanistyki i przepisuje jej słownik na nowo. W efekcie mamy do czynienia nie $\mathrm{z}$ tekstami, ale z danymi; nie z pracami, ale projektami; nie z teoria, ale z praktykowaniem teorii; nie $\mathrm{z}$ analizą kulturową, ale z produkcją narzędzi do analizy, a raczej analityki kulturowej ${ }^{2}$. Laboratorium wiąże się zatem $\mathrm{z}$ całkowitą przebudową humanistyki, która zapożycza kategorie z innych nauk, by stać się „nauką”.

Edukacja neoliberalna, kryzys ekonomiczny, przyspieszenie technologiczne, kryzys społeczny, polityczny i kulturowy, problemy ekologiczne te wszystkie czynniki zewnętrzne zmuszają do zmian strukturalnych i metodologicznych. Żyjemy w czasach konstruowania świata na nowo i, aby dokonać jego transformacji i zrozumieć jego kryzys, humanistyka zmuszona jest sama poddać się reorganizacji. Mówiąc za Latourem, to czas odejścia od tekstu, w stronę miejsca, gdzie te teksty powstają. Wejście do laboratorium oznacza zatem skierowanie uwagi nie na opis problemów, ale na ich translację w sztucznym, laboratoryjnym środowisku, a następnie ich zredukowanie, by zbadać ich podłoże, eksperymentalnie przetestować rozwiązania i ostatecznie zastosować je poza murami laboratorium.

Przeformułowanie humanistyki odbywa się zatem od pojęć do transformacjỉ. By zrozumieć jej przeobrażenia, należy przeanalizować koncepcje,

$1 \quad Ł$. Afeltowicz Modele, artefakty, kolektywy. Praktyka badawcza w perspektywie współczesnych studiów nad naukg, Wydawnictwo Naukowe UMK, Toruń 2012, s. 405.

2 L. Manovich The science of culture? Social computing, digital humanities, and cultural analytics, 2015, http://manovich.net/index.php/projects/cultural-analytics-social-computing (10.03.2016).

3 O przejmowaniu pojęć ścisłych przez humanistykę i wpływ tego na transformację humanistyki mówiłam w trakcie konferencji the American Comparative Literature Association's 2016 Annual Meeting na Uniwersytecie Harvarda w dniach 17-20.03.2016 r. Wystąpienie pt. Bringing categories from science into humanities practice: The implications for the public humanities miało miejsce w ramach seminarium Public Humanities in the Digital Age. Część artykułu poświęcona ekonomizacji uniwersytetu, humanistyce cyfrowej i kategorii laboratorium powstała na podstawie tego wystąpienia. 
którymi się posługuje, a które, jak stwierdza Mieke Bal, są „miniaturowymi teoriami"4. Koncepcje mają siłę performatywną i sprawczą - potrafią dogłębnie zmodyfikować dany obszar badawczy, po czym powędrować gdzieś indziej. Wędrowanie pojęć nie jest zatem niczym nowym, jednak podróż w jedną stronę już niekoniecznie. Pojęcia z nauk ścisłych (dane, kolektywność, narzędzia, analityka itd.) wkraczają na obszar humanistyki, modyfikując ją. Wyjście z pracowni do laboratorium wydaje się decyzją świadomą, ale podjętą pod presją czynników zewnętrznych. Artykuł To nie jest muzeum, to jest laboratorium ${ }^{5}$ kończyłam słowami, że nie mamy już odwrotu - czas wyjść z pracowni. Odwrotu już nie ma, bo laboratoryzacja świata stała się faktem. Nie możemy przewidzieć, czy do pracowni jeszcze nie powrócimy - może będzie to pracownia, jakiej jeszcze nie znamy: wirtualna, bez ścian i podziałów na instytuty ${ }^{6}$. Póki co humanistyka podejmuje wszelkie wyzwania i jeszcze nigdy nie miała tyle do zrobienia.

Strategia instytucjonalna jest podstawową metodą zwalczenia kryzysów na wielu frontach. W niniejszym tekście prześledzę drogę zmian strukturalnych humanistyki: od pracowni, przez centrum do laboratorium. Tworzenie humanistycznych laboratoriów (na gruncie amerykańskim określane jako „laby”) nie wzięło się jednak „znikąd”. Z tego też powodu proponuję spojrzeć na reorganizację humanistyki przez pryzmat teoretycznych przełomów i zwrotów, które stopniowo budowały fundament pod radykalne zmiany. W swoim szkicu proponuję zatem spojrzeć na reinstytucjonalizację humanistyki w kontekście zwrotu kulturowego, performatywnego, praktycznego i cyfrowego. Kluczowym momentem dla rozważań o powstawaniu humanistycznych laboratoriów okazują się lata 2008-2010 - czas kryzysu ekonomicznego, który szczególnie dotknął humanistykę. Bazując na analizach Google Trends, widzimy, że budowa humanistycznych labów (the humanities lab) drastycznie wzrasta po 2010 roku, a to z kolei nakłada się z rozwojem humanistyki cyfrowej. Okres ten określam zatem jako zwrot taktyczny w humanistyce, a jedną z metod wyjścia z kryzysu jest strategia instytucjonalna - budowanie laboratoriów.

4 M. Bal Wędrujące pojęcia w naukach humanistycznych. Krótki przewodnik, przeł. M. Bucholc, Narodowe Centrum Kultury, Warszawa 2012, s. 47. U. Pawlicka To nie jest muzeum, to jest laboratorium, "Czas Kultury” $2015 \mathrm{nr}$ 2, s. 60-65.

6 Nawiązuję tutaj do nowej idei uniwersytetu rozwijanej przez Christine Ortiz z Massachusetts Institute of Technology. J.R. Young MIT Dean takes leave to start new university without lectures or classrooms, "The Chronicle of Higher Education", 1.02.2016, http://chronicle.com/article/MIT-Dean-Takes-Leave-to-Start/235121, (10.03.2016). 


\section{XIX/XX wiek. Wyjście z laboratorium}

W XIX/XX wieku humanistyka na wzór nauk przyrodniczych przedstawia się jako dziedzina cechująca się rzetelnymi, precyzyjnymi i analitycznymi badaniami, poddającymi się klasyfikacji, parametryzacji i falsyfikacji. Jak zauważa Julie Thompson Klein, podobnie jak laboratoryjne próbki, humanistyczne obiekty mogły być manipulowane, wnikliwie analizowane, wymierzalne, skalowane oraz podporządkowane precyzyjnej metodologii? ${ }^{7}$. Nauki przyrodnicze były wówczas zdominowane przez teoriocentryzm, według którego "praca naukowa zostaje sprowadzona do logicznych operacji na elementach tego systemu"8. Praca laboratoryjna służyła wyłącznie do przetestowania teorii naukowej, a nie do jej wypracowania. Eksperymenty i praktyki badawcze były podporządkowane precyzyjnej teorii naukowej, której ścisłe zasady nie pozwalały wyjść poza dany system metodologiczny i konceptualny. Humanistyka ostatecznie postanawia uwolnić się z rygoru „teocentrycznego laboratorium" w celu zbudowania fundamentów własnej nauki. Wyjściu z laboratorium do biblioteki towarzyszy zwrot antypozytywistyczny, opisywany przez Annę Burzyńską jako czas kiedy „nauki humanistyczne usamodzielniły się i odłączyły od nauk przyrodniczych, powołując do życia własną, odrębną metodologię"

Wejście do biblioteki oznaczało eksplorowanie tekstów w celu sformułowania własnych podstaw teoretycznych. Nadszedł zatem zwrot strukturalny, któremu zawdzięczamy zbudowanie mocnego modelu naukowej teorii literatury. Paradygmat nowoczesny oparty na silnym uteoretyzowaniu nauki humanistycznej nie przetrwał jednak próby czasu. Szybko bowiem okazało się, że rygorystyczne teorie łatwo poddają się zakwestionowaniu i dekonstrukcji. Zatem celem kolejnego przełomu - poststrukturalnego - było ujawnienie sztuczności koncepcji teoretycznych i uwolnienie literatury z jarzma metodologii ${ }^{10}$. W ten sposób nachodzi kolejny zwrot kulturowy - poszukujący tym razem teorii w praktyce. Przyczynił się on do „otwarcia” teorii literatury na problemy zewnętrzne, których nie da się

7 J.T. Klein Humanities, Culture, and Interdisciplinarity. The Changing American Academy, State University of New York Press, Albany 2005, s. 28.

8 Ł. Afeltowicz Laboratoria w działaniu. Innowacja technologiczna w świetle antropologii nauki, Oficyna Naukowa, Warszawa 2011, s. 25.

9 A. Burzyńska Kulturowy zwrot teorii, w: Kulturowa teoria literatury. Główne pojęcia i problemy, red. M.P. Markowski, R. Nycz, Universitas, Kraków 2012, s. 44. 
opisać, korzystając tylko z jednego słownika. Pomnożenie języków, praktykowanie teorii, a w końcu wyjście z biblioteki do pracowni - to wszystko doprowadziło do zwrotu pragmatycznego, pytającego nie o istotę literatury, ale o sposoby jej działania. Nowe zadania w teorii literatury nałożyły się $\mathrm{z}$ kolei na powstanie nowych kierunków w nauce: zwrotu performatywnego i empirycznego.

\section{Performatywność, praktyka i technologie}

Zwrot performatywny, do którego doszło pod koniec XX wieku, w latach 70. i 8o., wiąże się ze wzrostem zainteresowania praktyk laboratoryjnych w filozofii nauki oraz w socjologii wiedzy naukowej. Szczególnie dwie publikacje odgrywają istotną rolę w tej zmianie paradygmatu nauki: Laboratory Life $e^{11}$ Bruno Latoura i Steve'a Woolgara oraz Technics and Praxis ${ }^{12}$ Dona Ihdego, obie wydane w 1979 roku. Nowa socjologia wiedzy naukowej zaproponowała nowe teorie badawcze określane jako konstrukcjonizm społeczny (social constructionism) oraz teoria aktora-sieci (actor network theory, ANT). Spojrzenie na naukę, wypracowane głównie przez teorię ANT Latoura, wiązało się z zaproponowaniem nowych praktyk społecznych, redefiniujących pojęcie "społeczeństwa”, rozumianego od tej pory jako konglomerat bytów ludzkich i nie-ludzkich (np. zwierząt, rzeczy, maszyn) ${ }^{13}$.

Nowe pojmowanie społeczeństwa wywarło wpływ na kolejną dziedzinę - filozofię technologii, w historii której wyraźnie widać zmiany teoretyczne zachodzące od lat 8o. XX wieku. Podstawowym celem nowej filozofii technologii ${ }^{14}$ było odejście od „tekstu" i „narracji”, implikujących człowieka i zapis jego doświadczeń, w stronę technologii, za pośrednictwem których nauka i człowiek są mediatyzowane i ucieleśnione. Ihde, jeden z najważniejszych filozofów technologii, stwierdza, że „bez instrumentów i laboratoriów nie

B. Latour, S. Woolgar Laboratory Life. The Construction of Scientific Facts, Princeton University Press, Princeton 1979.

D. Ihde Technics and Praxis, Reidel Publishers, Dordrecht 1979.

B. Latour Nigdy nie byliśmy nowocześni, przeł. M. Gdula, Oficyna Naukowa, Warszawa 2011; B. Latour Splatając na nowo to, co społeczne. Wprowadzenie do teorii aktora-sieci, przeł. A. Derra, K. Abriszewski, Universitas, Kraków 2010.

American Philosophy of Technology: the Empirical Turn, ed. by H. Achterhuis, trans. by R.P. Crease, Indiana University Press, Bloomington-Indianapolis 2001. New waves in philosophy of technology, ed. by J.K. Berg Olsen, E. Selinger, S. Riis, Palgrave Macmillan, New York 2009. 
byłoby nauki"15. Z tego też powodu badacze powinni skoncentrować się na analizie produktów materialnych, narzędzi i aparatury, które zapośredniczają doświadczenie i modyfikują ludzką percepcję. W konsekwencji tych rozpoznań nowa filozofia technologii głosi zwrot empiryczny i pragmatyczny, zakładający, że ludzka obserwacja jest ucieleśniona w praktycznych zastosowaniach narzędzi i instrumentów. Ludzka percepcja i doświadczenie nie mogą być zatem badane bez analizy praktycznych działań. Z tego też powodu, i z uwagi na fakt, że wszelkie analizy są zdeterminowane przez użyte w badaniach instrumenty, teoretycy odchodzą od pojęć „obiektywizacji” i „uniwersalności" badań, towarzyszących paradygmatowi reprezentatywności.

W tym też kontekście przejście od reprezentatywności do performatywności wydaje się zrozumiałe i oczywiste. Celem badań reprezentatywnych było obiektywne przedstawienie natury, wyprodukowanie wiedzy stałej i sparametryzowanej oraz wprowadzenie ściśle sprecyzowanej metodologii16. Podczas gdy reprezentatywność wiązała się z uprzywilejowaniem ludzkiej perspektywy, performatywność charakteryzuje się zwróceniem uwagi na wszystkie byty, posiadające sprawczą ${ }^{17}$ (agency) właściwość „wytwarzania rzeczy" (making things). Performatywne oblicze nauki podkreśla zatem znaczenie praktyki, doświadczenia, sprawczości i ruchu w jego różnych postaciach. Zwrot perfomatywny odrzuca obiektywny opis świata, który wiąże się z jednym - ludzkim - punktem widzenia.

Nadejście performatywności wiąże się z szeregiem zmian i wyzwań, m.in. z przejściem od teorii do praktyki. Podczas gdy postmodernizm nobilitował teorię, tekst i wiedzę produkowaną poza praktyką, zwrot empiryczny w filozofii nauki wprowadził nowe podejście badawcze, koncentrujące się na praktyce, technologii i doświadczeniu. Przejście - od perspektywy tekstualnej postmodernizmu w stronę praktyki empirycznej - zauważalne jest we wspomnianej nowej filozofii technologii (Bergmann, Ihde, Verbeek, Feenberg, Graham, Pickering) oraz w humanistyce cyfrowej (Schreibman, Siemens, Unsworth,

15 D. Ihde Postphenomenology and Technoscience. The Peking University Lectures, SUNY Press, Albany 2009, s. 7.

16 Por. A. Pickering The Mangle of Practice: Time, Agency, and Science, The University of Chicago Press, Chicago-London 1995, s. 5-9.

17 O sprawczości: A. Gell Art and Agency: an Anthropological Theory, Oxford University Press, Oxford 1998; B. Latour Splatajqc na nowo to, co społeczne. Materiality, ed. by D. Miller, Duke University Press, Durham-London 2005; P.P. Verbeek What Things Do: Philosophical Reflections on Technology, Agency, and Design, trans. by R.P. Crease, Pennsylvania State University Press, University Park 2005. 
Burdick, Drucker, Lunenfeld, Presner, Schnapp, Kirschenbaum, Berry). Szczególnie ta druga dyscyplina odgrywa kluczową rolę w „post-teoretycznym wieku", kiedy teoria jest zastępowana przez kwestie praktyczne, związane z „badaniem, analizą, syntezą i prezentacją informacji w elektronicznej formie"18. Celem humanistyki cyfrowej jest bowiem zastosowanie mediów cyfrowych do wypracowania narzędzi humanistycznych, służących do „przekazywania i nauczania tradycyjnej wiedzy za pośrednictwem kolektywnych, sieciowych i informacyjnych technologii"19. Humanistyka cyfrowa kładzie zatem zdecydowany nacisk na produkcję kulturowych i cyfrowych artefaktów ${ }^{20}$.

Zmiana kierunku w badaniach, od teorii do praktyki (sprawczości, działania, doświadczenia i produkcji) wiąże się zatem z ostatnim, sygnalizowanym już wcześniej, przejściem od tekstu do technologii. Odwołując się do rozważań Davida M. Kaplana, zwrot technologiczny można rozumieć jako odwrót od tekstu, związanego z ludzką narracją, w stronę technologii, uzyskujących prawo do wnikliwych analiz ich indywidualnych właściwości i „spisywania” ich własnych historiii ${ }^{21}$. Efektem tego przejścia jest zainicjowanie nowych kierunków badawczych, takich jak software studies (Kittler, Manovich, Flusser, Fuller, Berry, Galloway), platform studies (Montfort, Bogost, Wardrip-Fruin), code studies $^{22}$ (Marino, Montfort, Bogost), archeologia mediów ${ }^{23}$ (Zielinski, Ernst, Parrika) i fenomenologia mediów ${ }^{24}$ (Hayles, Hansen, Paterson). Zwrot

18 M.G. Kirschenbaum Mechanism. New Media and the Forensic Imagination, The MIT Press, Cambridge-London 2008, s. 56.

19 A. Liu The Laws of Cool: Knowledge Work and the Culture of Information, University of Chicago Press, Chicago 2004, S. 312.

A. Burdick (i in.) Digital Humanities, The MIT Press, Cambridge-London 2012, s. 10.

D.M. Kaplan How to Read Technology Critically, w: New Waves in Philosophy of Technology, s. 83-99.

M.C. Marino Critical code studies, "Electronic Book Review" 4.12.2006, http://www.electronicbookreview.com/thread/electropoetics/codology (3.02.2016); N. Montfort Programming for Fun, Together, w: Remediating the Social, ed. by S. Biggs, ELMCIP, University of Bergen, Bergen 2012, s. $15-19$.

23 S. Zielinski Archeologia mediów, przeł. K. Krzemieniowa, Oficyna Naukowa, Warszawa 2010. Media archaeology. Approaches, Applications, and Implications, ed. by E. Huhtamo, J. Parikka, University of California Press, Berkeley-Los Angeles 2011; J. Parikka What is media archaeology? Polity Press, Cambridge 2012; W. Ernst Digital Memory and the Archive, University of Minnesota Press, Minneapolis 2012.

24 M.B.N. Hansen New Philosophy for New Media, The MIT Press, Cambridge-London 2004; M. Paterson The Senses of Touch: Haptics, Affects and Technologies, Bloomsbury Academic, London 
technologiczny może być postrzegany jako neoMcLuhanowska perspektywa badań nad mediami, gdzie program i produkcja odgrywają kluczową rolę w interpretacji kultury.

\section{Korporacjonizm uniwersytetu i kryzys humanistyki}

Zwrot w stronę praktykowania nauk humanistycznych nasila się w pierwszym dziesięcioleciu XXI wieku, w momencie przeobrażania uniwersytetu na wzór korporacyjnego przedsiębiorstwa. Pojawiają się wówczas takie publikacje jak The Practice Turn in Contemporary Theory ${ }^{25}$ (2001) - o zwrocie praktycznym, Theory's Empire ${ }^{26}$ (2005) - m.in. o kryzysie teorii i humanistyki; oraz Representation in Scientific Practice. Revisited ${ }^{27}$ (2014) - znaczące, ponowne wydanie publikacji z 1988/1990, implikujące powrót do reprezentatywności w nauce.

W klimacie neoliberalnej edukacji i ekonomizacji uniwersytetu humanistyka jest narażona na usunięcie z europejskiego uniwersytetu, o czym pisze Rosi Braidotti w swej ważnej publikacji The Posthuman z 2013 roku $^{28}$. Uniwersytet zaczął być postrzegany jako biznes nastawiony na zysk, a zajęcia i wiedza traktowane jako produkt, który należy „sprzedać” i jeszcze na nim zarobić. W świetle rygorów korporacyjnych uniwersytet miał stać się miejscem profitowym i atrakcyjnym, dostarczającym produkty dające się sparametryzować wedle norm rynkowych. Mimo że uniwersytet i zaawansowany kapitalizm są niekompatybline, jak podkreśla Terry Eagleton ${ }^{29}$, korporacjonizm uniwersytetu nie został wstrzymany. Szczególnym obiektem ataku stała się humanistyka, dla której dotkliwe okazały się standardy marketingowe oraz związane z nimi wyzwanie sparametryzowania wiedzy humanistycznej i określenia jej stopnia zaaplikowania.

2007; N.K. Hayles How We Think: Digital Media and Contemporary Technogenesis, University of Chicago Press, Chicago 2012.

The Practice Turn in Contemporary Theory, ed. by T.R. Schatzki, K. Knorr Cetina, E. von Savigny, Routledge, London-New York 2001.

Theory's Empire. An Anthology of Dissent, ed. by D. Patai, W.H. Corral, Columbia University Press, New York 2005.

27 Representation in Scientific Practice. Revisited, ed. by C. Coopmans, J. Vertesi, M. Lynch, S. Woolgar, The MIT Press, Cambridge-London 2014.

R. Braidotti The Posthuman, Polity Press, Cambridge 2013, s. 10.

29 T. Eagleton The death of universities, "The Guardian" 17.12.2010, http://www.theguardian.com/ commentisfree/2010/dec/17/death-universities-malaise-tuition-fees (10.03.2016). 
Pogłębieniu kryzysu sprzyjały lata 2008-2010 - czas załamania finansowanego w Stanach Zjednoczonych, dotkliwego także dla rynków europejskich. Kryzys ten zapoczątkował plan wdrażania reform w szkolnictwie wyższym, dyskryminujących małe uniwersytety i minimalizujących rolę humanistyki, w celach „podporządkowania uniwersytetów bieżącym trendom gospodarczym i grze przypadkowych interesów"30. Od tego momentu pojawia się fala publikacji poświęconych kryzysowi uniwersytetu i humanistyki ${ }^{31}$, fala protestów środowiska akademickiego wobec zamykania kierunków humanistycznych, czego egzemplifikacją była dyskusja o likwidacji filozofii na Uniwersytecie w Białymstoku, oraz sprzeciw studentów niezgadzających się na komercjalizację uczelni. Za przykład niech posłuży rezygnacja wszystkich studentów z Roski School of Art and Design na University of Southern California w 2015 roku jako znak sprzeciwu wobec nowej misji uniwersytetu, zakładającej przyrost pokolenia inwestorów i liderów w globalnych przemysłach ${ }^{32}$.

W obliczu kryzysu instytucjonalnej nauki, komercjalizacji uniwersytetu i procesu kapitalizacji wiedzy humaniści podejmują różne strategie od kontestacji3 ${ }^{33}$,jak utworzenie Komitetu Kryzysowego Humanistyki Polskiej w 2013

30 Komitet Kryzysowy Humanistyki Polskiej, Działalność, http://kkhp.pl/historia-i-dzialalnosc/ (30.06.2016)

T. Eagleton The death of universities; N. Carr The crisis in higher education, "MIT Technology Review" 27.09.2012, https://www.technologyreview.com/s/429376/the-crisis-in-higher-education/ (03.02.2016); M.C. Nussbaum Not for Profit: Why Democracy Needs the Humanities, Princeton University Press, Princeton 2012; S. Collini What Are Universities For?, Penguin, London 2012; The Humanities and Public Life, ed. by P. Brooks, H. Jewett, Fordham University Press, New York 2014; S. Conn How the crisis of the humanities is like the Greek economy, "The Chronicle of Higher Education" 15.11.2015, http://chronicle.com/article/How-the-Crisis-of-the/234185 (03.02.2016); Nie pozwólmy utopić uniwersytetu. Rozmowę z prof. Przemysławem Czaplińskim przeprowadziła Natalia Mazur, 2015, http://poznan.wyborcza.pl/poznan/1,36001,18008969,Czaplinski_ Nie_pozwolmy_utopic_uniwersytetu.html (03.02.2016); numery tematyczne: Koniec uniwersytetu?, „Bliza” 2015 nr 1 (22), Kryzys uniwersytetu ,"Czas Kultury” 2015 nr 3.

R. White A few good reasons to drop out of art school, "The New Yorker" 22.05.2015, http:// www.newyorker.com/news/news-desk/a-few-good-reasons-to-drop-out-of-art-school (10.03.2016).

33 O oddolnym „ruchu oporu” pisała: E. Nawrocka „Bunt nie ustaje, bunt się udorzecznia”, "Bliza” $2015 \mathrm{nr} 1$ (22), s. 29-38. W artykule tym Nawrocka przedstawia różne działania podejmowane w celach sprzeciwu wobec komercjalizacji szkolnictwa wyższego, takie jak organizacja debat i konferencji (Wściekłość i oburzenie. Obrazy rewolty w kulturze współczesnej, konferencja zorganizowana na Wydziale Humanistycznym Uniwersytetu Gdańskiego w 2012 roku, debata Edukacja i ekonomia na tym samym uniwersytecie w 2012 roku, Nauka światowa - Uniwersytet - Profesor - Student na Uniwersytecie Rzeszowskim w 2013 roku, organizacja I Kongresu 
roku, przez wycofanie, akceptację po poddanie się logice ekonomicznej widoczne choćby w formie nadprodukcji książek w imię zasady „publikuj albo giń", o czym kontrowersyjnie pisał Lindsay Waters w swej książce Zmierzch wiedzy. Przemiany uniwersytetu a rynek publikacji naukowych ${ }^{34}$.

Ostatnia postawa w konsekwencji, niestety, prowadzi do osłabienia profesjonalizacji humanistyki, do obniżenia wartości jej pracy nastawionej na produkcję, a nie na krytyczną refleksję, oraz do wzrostu specjalizacji i „ekspertów" w humanistyce. Mechanizmy te przyczyniają się do pogłębienia kryzysu humanistyki, a nie do jego przezwyciężenia. Jonathan Gottschall w swej publikacji Literature, Science, and a New Humanities z 2008 roku prowokacyjnie stwierdza, że jedynym wyjściem pokonania kryzysu jest zbliżenie się humanistyki do nauki ${ }^{35}$.

\section{Zwrot taktyczny. W stronę unaukowienia humanistyki}

Costas Stratilatis postrzega unaukowienie socjologii i humanistyki jako dostosowanie epistemologicznych i metodologicznych założeń pozytywizmu - empirycznych nauk przyrodniczych ${ }^{36}$. Humanistyka jak część nauk empirycznych została zaprezentowana przez Rensa Boda w Historii humanisty $k \imath^{37}$. Bod uznaje humanistykę za naukę opartą na obserwacji, przyjmuje za cel poszukiwanie zasad i schematów w materiałach historycznych. Zwracając uwagę na podjęte założenie metodologiczne, nie można nie odnieść się do wspomnianego kryzysu humanistyki, którego jednym z zarzutów jest jej niepraktyczność. Bod obala mit niepragmatyczności humanistyki, której celem jest odrzucenie dotychczasowej tożsamości na rzecz przejęcia strategii z nauk ścisłych.

Dydaktyki Polonistycznej na Uniwersytecie Jagiellońskim w 2013 roku, rozpoczynającego się od debaty Czy świat potrzebuje humanistów? Polonistyka na uniwersytecie wobec przemian późnej ponowoczesności), aktywność stowarzyszenia Obywatele Nauki czy utworzenie Komitetu Kryzysowego Humanistyki Polskiej w 2013 roku.

L. Waters Zmierzch wiedzy. Przemiany uniwersytetu a rynek publikacji naukowych, przeł. T. Bilczewski, Homini, Kraków 2009.

35 J. Gottschall Literature, Science, and a New Humanities, Palgrave Macmillan, New York 2008, s. xii. in Science and Environmental Politics" 2014 No. 13, s. 177, doi: 10.3354/esepo0144. 
Zdefiniowanie tożsamości na nowo wiąże się z określeniem różnic między humanistyką a naukami ścisłymi, a raczej z ostatecznym przeciwstawieniem się twierdzeniom o rozdzielności tych nauk. Rozgraniczenie nauk w XVIII wieku okazuje się chwiejne i dyskusyjne pod koniec XX wieku. Tezy Wilhelma Dilthey'a i Wilhelma Windelbanda z XIX wieku nie da się już obronić w obliczu inter- i transdyscyplinarności badań. Podział na nauki przyrodnicze - nomotetyczne, koncentrujące się na tym, co ogólne $i$ systematyczne i zajmujące się wyjaśnianiem oraz na nauki humanistyczne - idiograficzne, których funkcją jest zrozumienie niepowtarzalnego, jednostkowego wydarzenia $^{38}$ - staje się sztuczny i nie daje się już dłużej utrzymać. Mimo że nadal możemy spotkać się z rozróżnieniem na nauki nomotetyczne i ideograficzne, teoretyczne i doświadczalne, spekulatywne i praktyczne, to jednak podziały te zostają zniesione przez współczesne badania dowodzące, że zarówno humanistyka może mieć znamiona praktyczne ${ }^{39}$, jak i nauki ścisłe mogą opierać się wyłącznie na założeniach teoretycznych - wystarczy bowiem przywołać fizykę teoretyczną, której wieści się kryzys z powodu niemożności eksperymentalnego dowodzenia jej tez ${ }^{40}$. Obalenie zatem mitu o rozdzielności nauk i odrzucenie przypisywanych im etykiet jest pierwszym krokiem na drodze do wyjścia z kryzysu humanistyki. Celem jest bowiem udowodnienie, że nie da się oderwać humanistyki od reszty nauk, gdyż właśnie ta „reszta” staje się obiektem badawczym humanistów.

Strategia unaukowienia humanistyki przybiera zatem różne formy dostrzegalne w zmianach instytucjonalnych (budowanie laboratoriów), materiałach badawczych („dane” zamiast „tekstów”), zaaplikowanej metodologii (analityka kulturowa), w sposobie prowadzenia badań (praktyki kolektywne) oraz w metodach ewaluacji pracy (parametryzacja, prowadzenie rankingów uczelnianych). Wskazane przesunięcia udowadniają, że humanistyka, zmuszona do bycia empiryczną i pragmatyczną, coraz bardziej zbliża się do nauki, by owe właściwości nabyć.

Jednym ze źródeł procesu unaukowienia humanistyki jest rozwój technologii, narzędzi informatycznych oraz cyberinfrastruktury. Zwrot

38 Tamże, s. 22.

39 Zob. Teoria - literatura - życie. Praktykowanie teorii w humanistyce współczesnej, red. A. Legeżyńska, R. Nycz, Wydawnictwo IBL PAN, Warszawa 2012.

40 A. Frank, M. Gleiser A crisis at the edge of physics, "The New York Times" 5.06.2015, http:// www.nytimes.com/2015/06/o7/opinion/a-crisis-at-the-edge-of-physics.html?ref=opinion (16.06.2015). 
technologiczny czy cyfrowy doprowadza do postrzegania wiedzy opartej na czynnościach praktycznych oraz wykorzystywaniu analitycznych narzędzi w działaniach kognitywistycznych. Wkroczenie nauki na teren humanistyki widać było na zorganizowanej w 2013 roku w Dolinie Krzemowej konferencji pt. „IEE International Conference on Big Data”. Sesja ta przyczyniła się do spopularyzowania idei budowania „Big Humanities”, na wzór „Big Science”, której celem ma być produkcja narzędzi cyfrowych do generowania, obrabiania, modyfikowania, organizowania i wizualizowania danych ${ }^{41}$. Od tego momentu humanistyka odeszła od "tekstu" w stronę „danych", ogłoszonych jako big thing ${ }^{42}$ w humanistyce. Badania nad danymi umożliwiły humanistyce stanie się dziedziną "produktywną" (rozwój teorii produktywnych zamiast krytycznych), „praktyczną” (tworzenie użytecznych narzędzi) i „materialną” (wizualizacja wyników badań w formie map, grafiki, modeli czy symulacji). Szczególnie ostatnia praktyka tworzenia „faktów widzialnych" w formie wizualizacji danych staje się coraz bardziej popularna i atrakcyjna, przyczyniając się przy tym do formułowania "nauki o kulturze"43 (the science of culture). Termin Manovicha kładzie nacisk na kwestię unaukowienia badań kulturoznawczych, opartych na metodach ilościowych, a nie jakościowych. Odejście od analizy w stronę analityki jest zatem jednym z przejawów stopniowej scientyzacji humanistyki.

Zwrot taktyczny w humanistyce oznacza zatem rozwój takich kierunków, które wpiszą się w narzucony przez neoliberalną edukację model nauki opartej na kryteriach rynkowych. Celem jest zmodyfikowanie i rozwój humanistyki, która udowodni, że tak jak nauka, potrafi być empiryczna i praktyczna. W takich warunkach powstaje humanistyka cyfrowa.

\section{Zaaplikowanie humanistyki. Rozwój humanistyki cyfrowej}

Richard Grusin i Rita Raley w swych krytycznych szkicach poświęconych humanistyce cyfrowej nie stronią od twierdzeń, że dyscyplina ta jest strategiczną odpowiedzią na kryzys w humanistyce. Grusin zadaje prowokacyjne pytanie o zbieżność rozwoju humanistyki cyfrowej z kryzysem finansowym

41 Zob. Ch.L. Borgman Scholarship in the Digital Age. Information, Infrastructure, and the Internet, The MIT Press, Cambridge-London 2007, s. 6-8. blogs/cathy-davidson/2008/07/30/cultural-analytics-next-big-thing (16.06.2015). 
po 2008 roku ${ }^{44}$. Raley z kolei podkreśla, że humanistyka cyfrowa szczególnie dobrze określiła swoje miejsce, odpowiadając na żądania administracyjne i publiczne dzięki produkcji wiedzy użytecznej. W końcu dzięki zastosowaniu narzędzi ilościowych jej badania łatwo poddają się kwantyfikacji ${ }^{45}$. Badacze dodają, że humanistyka cyfrowa ochoczo akcentuje własny aspekt pragmatyczny, powtarzając, że jej celem jest making things. W konsekwencji wzmacnianie wartości praktycznej wywołuje napięcie między humanistami cyfrowymi a tradycyjnymi.

Humanistyka cyfrowa obejmuje zatem wszystko to, co niezbędne do restrukturyzacji i ożywienia humanistyki: eksperymentalne badania, sparametryzowane narzędzia, metody analityczne, badania zespołowe oraz laboratorium. Celem humanistyki cyfrowej są badania oparte na danych, które należy zorganizować, opracować i zwizualizować. W efekcie pracy analitycznej dochodzi do wytwarzania teorii, wywiedzionej z eksperymentalnych badań. Przykładem są badania ilościowe w celach ukazania ewolucji gatunków literackich i dziejów twórczości literackiej, prowadzone przez Franco Morettiego, założyciela Stanford Literary Lab i twórcę idei distant reading ${ }^{\mathbf{4 6}}$.

Coraz częściej pojawiają się pytania o rolę instrumentalną humanistyki cyfrowej. Przywołuje się bowiem jej cechy, odpowiadające współczesnym wymaganiom rynkowym, zasadom unaukowienia humanistyki i kryteriom otrzymywania grantów badawczych. Humanistyka cyfrowa bez wątpienia przyczyniła się do ogromnej transformacji humanistyki, gdzie „praktyka” nie jest już ujmowana jako użyteczna metafora. Dała ona szansę wyjścia z pogłębiającego się kryzysu. Cena okazuje się wysoka, ale to nie koniec zwrotu taktycznego.

Kolejnym krokiem powinno być przełamanie twierdzeń, że humanistyka cyfrowa jest wyłącznie odpowiedzią na kryzys w humanistyce, wyjście poza funkcję instrumentalną - do czego nawoływał Alan Liu w swym ważnym artykule Where is Cultural Criticism in the Digital Humanities? ${ }^{47}$ - intensyfikacja roli

44 R. Grusin The dark side of digital humanities: dispatches from two recent mla conventions , "differences" 2014 Vol. 25 , No. 1, s. 79-80.

45 R. Raley Digital humanities for the next five minutes, "differences" 2014 Vol. 25, No. 1, s. 5.

46 F. Moretti Graphs, Maps, Trees: Abstract Models for a Literary History, Verso, London-New York 2007; F. Moretti Distant reading, Verso, London 2013.

47 A. Liu Where is Cultural Criticism in the Digital Humanities?, w: Debates in the Digital Humanities, ed. by M.K. Gold, University of Minnesota Press, Minneapolis 2012, http://dhdebates.gc.cuny. edu/debates/text/20 (30.06.2016). 
krytycznej i rozwój potencjału humanistyki cyfrowej, która może być równorzędnym partnerem humanistyki. Celem powinno być zaaplikowanie myślenia humanistycznego w nauce: krytycznego myślenia, głębokiej interpretacji danych i analiz dekonstrukcyjnych. Następnym etapem powinno być zatem wzmacnianie "podejścia humanistycznego" (the humanities approach), czemu poświęca uwagę Johanna Drucker ${ }^{48}$. Póki co, prześledźmy fundamentalną strategię pokonania owego kryzysu: tworzenie laboratorium.

\section{Strategie instytucjonalne. Budowanie nowych porządków władzy}

„«Nauka to polityka uprawiana innymi środkami». Nie jest to jednak polityka, gdyż każda władza jest zawsze blokowana przez jakąś przeciwwładzę. Liczy się to, że nauki laboratoryjne stanowią te «inne środki», świeże, nieprzewidywalne źródła przemieszczeń, które są o tyle potężniejsze, o ile są nieprzewidywalne i niejednoznaczne"49. Latour w swym znaczącym tekście Dajcie mi laboratorium, a poruszę świat wykazuje, że laboratorium, zwyczajne miejsce prowadzenia badań, staje się świetną „konstrukcją technologiczną służącą odwracaniu hierarchii sił"50. Jego trafna uwaga dotycząca tego, że „widzimy laboratoria, lecz ignorujemy ich konstrukcję", może zostać rozszerzona na każde miejsce praktykowania badań naukowych. Każdorazowo miejsce bowiem implikuje proces poznawczy, materiały i wytwory badawcze. Jak słusznie zauważa Ewa Rewers: „Miejsce, w którym praktykuje się badanie, zarówno to obciążone chaotycznym ciagiem skojarzeń metaforycznych (warsztat), jak nazywane wprost (biblioteka), nawiązuje zawsze od określonych praktyk, mówiących dużo o tym, czym humanistyczne badanie powinno być, z czego czerpie inspiracje, co je dyscyplinuje"51. To zatem przestrzeń decyduje o tym, jak prowadzi się badania i jak postrzega się daną dyscyplinę. Miejsce jest więc konstrukcją upolitycznioną, decydującą o układzie sił, a jego zmiana oznacza budowanie nowych struktur i nowych porządków władzy.

48 J. Drucker Humanities approaches to graphical display „Digital Humanities Quarterly” 2011 Vol. 5, No. 1, http://www.digitalhumanities.org/dhq/vol/5/1/000091/000091.html (16.06.2015).

B. Latour Dajcie mi laboratorium a poruszę świat, przeł. K. Abriszewski, Ł. Afeltowicz, „Teksty Drugie" $2009 \mathrm{nr} 1 / 2$, s. 191.

50 Tamże, s. 187.

51 E. Rewers Praktyka jako badanie: nowe metodologie w humanistyce, w: Teoria - literatura - życie..., s. 48. 


\section{Pracownia. Tkanie tekstu w pojedynkę}

Paradygmat postmodernistyczny i zwrot narratologiczny w drugiej połowie XX wieku wiązały się ze wzmocnieniem roli miejsca, w którym gromadzi się i wytwarza teksty: biblioteka, archiwum czy warsztat. Pracownia stała się terenem, w którym humaniści tworzą teorie „w pojedynkę”, by następnie je zrewidować w trakcie seminarium naukowego, przejawiającego się jako „obszar pojedynków”: „Seminaria badawcze w humanistyce można interpretować nie tylko jako przestrzeń dla wypracowania nowych koncepcji, co jako obszar pojedynków zakładających odpieranie zarzutów wymierzonych w rozwinięte w prywatnych pracowniach koncepcje lub systemy myślowe"52. Seminarium naukowe służy zaprezentowaniu własnych badań, ich przeformułowaniu czy uzupełnianiu. Pełni zatem rolę, jak zauważa Łukasz Afeltowicz, „środka testowania hipotez"53, a nie miejsca eksperymentalnego wytwarzania teorii.

Pracownia implikuje nie tylko sposób prowadzenia badań (samodzielne prace teoretyczne), materiał badawczy (teksty pisane), lecz także obraz humanisty-myśliciela, który za zamkniętymi drzwiami swego gabinetu konstruuje abstrakcyjne teorie naukowe. Pracownia humanisty przyczyniła się do wytworzenia i wzmocnienia hierarchii badaczy oraz określonej na zasadzie statusu relacji między profesorem i studentem. Odejście od laboratorium do pracowni oznaczało metaforyczne „zamknięcie” się humanistów w gabinetach i tym samym kategoryczne ustanowienie podziałów na dyscypliny naukowe.

„Pracownia” przyczyniła się zatem do postawienia granic między dyscyplinami (humanistyką a naukami ścisłymi), między badaczami (każdy pracownik posiada swój własny gabinet), między zajęciami a konsultacjami (spotkania z promotorem raz na tydzień), między uniwersytetem a przestrzenią publiczną czy między pracą teoretyczną a praktyczną. Wszystkie te cechy miały zostać zniesione przez dwie kolejne koncepcje miejsc.

\section{Centrum. W stronę budowania wspólnoty}

Instytucjonalną strukturą służącą wzmocnieniu pozycji humanistyki (cyfrowej) miały być centra badawcze zbudowane na wzór naukowych ośrodków badawczych. Klein zauważa, że słowo „centrum” jest ironiczne, ponieważ wcale nie zapewnia wyższego statusu i większej reputacji jednostki niż określenie „instytut”. Centrum jest zazwyczaj skromne w swych rozmiarach 
i zlokalizowane gdzieś w przestrzeni "między” dominującymi strukturami uniwersytetu. W efekcie centrum jest nisko finansowane w porównaniu z innymi jednostkami ${ }^{54}$.

Centrum miało służyć przede wszystkim „wyjściu” z pracowni i „otwarciu” się humanistyki na przestrzeń akademicką i publiczną. Jego celem jest zbudowanie wspólnoty (community) akademickiej, ponad podziałami na dyscypliny naukowe. Centrum było krokiem w stronę rozwoju humanistyki opartej na badaniach interdyscyplinarnych oraz wytworzenia nowej formy wiedzy, osiągniętej dzięki współpracy, wymianie, zaangażowaniu i eksplorowaniu technologii. O ile laboratorium kładzie nacisk na produkcję i innowacyjność badań, o tyle centrum stawia na rozwój edukacji, wspólnoty i promocji humanistyki. Centrum jest miejscem spotkań, wykładów i warsztatów. Ma służyć popularyzacji wiedzy na uniwersytecie i poza nim - stąd podkreśla się aspekt humanistyki publicznej w rozwoju humanistyki cyfrowej.

Centrum $^{55}$ pełni zatem następujące funkcje: budowanie kolekcji i archiwów cyfrowych, dostarczanie narzędzi technologicznych, obsługiwanie informacyjnych portali uczelni, koordynacja cyfrowych projektów (Centrum Humanistyki Cyfrowej Instytutu Badań Literackich PAN w Warszawie), organizowanie szkoleń, warsztatów i konferencji, oferowanie konsultacji, badanie wpływu technologii cyfrowych na prowadzenie badań naukowych, popularyzacja włączenia narzędzi cyfrowych do badań i nauczania (The Digital Humanities Center na Columbia University), rozwijanie zaawansowanych form nauczania cyfrowego, wykorzystywanie nowych technologii w badaniach literackich, budowanie pomostu między humanistyką, nauką i informatyką, między kadrą i studentami oraz między uniwersytetem i szerszą społecznością (Center for the Humanities na New York University).

\section{Laboratorium. Kolektywne wytwarzanie rzeczy}

Centrum, w przeciwieństwie do laboratorium, podkreśla znaczenie przestrzeni jako miejsca spotkań i wspólnoty. Stanowi ono ważny krok w stronę

54 J.T. Klein Interdisciplining digital humanities. Boundary work in an emerging field, University of Michigan Press, Ann Arbor 2015, e-book, lokalizacja 1771.

55 Więcej o centrach humanistyki cyfrowej: N. Fraistat The Function of Digital Humanities Centers at the Present Time, w: Debates in the Digital Humanities, http://dhdebates.gc.cuny.edu/debates/text/23 (30.06.2016). CenterNet: An international network of digital humanities centers, https://dhcenternet.org/ (30.06.2016). 
„wyjścia” humanistyki poza mury pracowni i uniwersytetu. Laboratorium z kolei kładzie nacisk już nie tyle na budowanie wspólnoty, ile na kolektywną pracę i produkcję materiałów. Laboratorium determinują następujące określenia: interdyscyplinarność, współpraca (collaboration w miejsce community), produkcja, innowacyjność i eksperymentalność.

Koncepcja laboratorium, angażującego myśl humanistyczną, pojawiła się jako forma instytucji kultury, dążąca do jej publicznego otwarcia, nawiązania współpracy z nauką, przyciągnięcia obywateli do współtworzenia i wspierania instytucji, popularyzacji wiedzy demokratycznej oraz zasady do it yourself, a także wzmocnienia idei humanistyki publicznej. Za egzemplifikację mogą posłużyć laboratoria miejskie oraz medialaby. Miejskie laby, opisywane przez Ewę Rewers na przykładzie Culture Lab Detroit, za cel stawiają sobie utworzenie przestrzeni otwartych spotkań, komunikacji interpersonalnej, dyskusji interdyscyplinarnych i rozwiązywania problemów konkretnego miasta $^{56}$. Z kolei Medialab, zorganizowany po raz pierwszy w Polsce w Chrzelicach w 2010 roku, prezentuje nową koncepcję instytucji kultury opartej na otwartości, przejawiającej się w „etosie wymiany informacji i wiedzy”, modelu współpracy „wykluczającej sztywną hierarchię, a stawiającej na otwarty proces, w którym mieszają się wymiary: edukacyjny, twórczy i produkcyjny"s7. Przywołane nowe formy kultury zaproponowały podejście laboratoryjne, polegające na pracy kolektywnej, interdyscyplinarnej, interinstytucjonalnej i ahierarchicznej, kładące nacisk na eksperymenty i innowacje technologiczne oraz precyzyjnie badające to, co dzieje się „pod maską hardware'u”.

Na gruncie nauki laboratorium przeszło znaczącą transformację w XVII wieku $\mathrm{z}$ „warsztatu rzemieślniczego" $\mathrm{w}$ „miejsce nauki”, charakteryzujące się wyspecjalizowaną aparaturą i instrumentami wymagającymi zarówno umiejętności manualnych, jak i wiedzy konceptualnej dotyczącej ich konstrukcji, obsługi i wdrożenia ${ }^{58}$. Budowa laboratoriów naukowych przyczyniła się do rozwoju nowoczesnego zrozumienia wiedzy, jako wiedzy zdobywanej poprzez praktykę, wykorzystywanie instrumentów i manipulację narzędziami.

56 E. Rewers Kulturowe studia miejskie. Projekt badań transdyscyplinarnych, "Kultura Współczesna” 2014 nr 4, s. 136; Kulturowe studia miejskie. Wprowadzenie, red. E. Rewers, Narodowe Centrum Kultury, Warszawa 2014. Medialab. Instrukcja obsługi, red. M. Filiciak, A. Tarkowski, A. Jałosińska, Fundacja Ortus, Chrzelice 2011, s. 13.

58 A.E. Earhart The Digital Humanities as a Laboratory, w: Between Humanities and the Digital, ed. by P. Svensson, D.T. Goldberg, The MIT Press, Cambridge-London 2015, S. 392. 
„Laboratorium w biologii, fizyce, chemii nie jest jedynie miejscem nagromadzenia rzadkich próbek, pomysłowych prezentacji czy skomplikowanych instrumentów. Stanowi ono również przestrzeń umożliwiającą badaczom negocjowanie oraz kolektywne rozwiązywanie technicznych, metodologicznych i teoretycznych aspektów badań" ${ }^{59}$. Humanistyka pozbawiona jest analogicznego miejsca, gdyż dotychczas jej praca nie opierała się na badaniach kolektywnych, interdyscyplinarnych, realizowaniu dużych projektów grantowych wymagających drogiej i zaawansowanej aparatury technologicznej. Skąd zatem potrzeba budowy nowej instytucji, reorganizującej całą pracę humanisty?

Gina Hiatt w artykule We Need Humanities Labs manifestacyjnie głosi potrzebę utworzenia laboratoriów w humanistyce, nie tylko dlatego, że materiał badawczy humanisty zmienił się i wymaga nowych warunków pracy i nowych metodologii, lecz przede wszystkim, by zmodyfikować tradycyjną pracę humanisty, która nie jest już skuteczna ${ }^{60}$. Hiatt podkreśla m.in. niewydajność pracy „w pojedynkę", nieefektywne spotkania seminaryjne raz w tygodniu, brak zaplecza technologicznego czy niskie finansowanie badań.

Transformację humanistyki można przeprowadzić wyłącznie dzięki jej reinstytucjonalizacji. Laboratorium odgrywa zatem następującą rolę: pragmatyczną (ukazanie pracy humanisty w świetle praktycznym), organizacyjną (zmiana pozycji humanistyki w nauce), finansową (wpływ na zwiększenie finansowania humanistyki jako dziedziny opłacalnej), metodologiczną (zmiana procesu kognitywnego i badawczego), innowacyjną (pobudzenie badań eksperymentalnych w humanistyce) oraz integracyjną (nacisk na otwarcie instytucji nauki i prowadzenie badań transdyscyplinarnych).

Praca humanisty w laboratorium ulega modyfikacji - staje się kolektywna i systematyczna (członkowie spotykają się niemal codziennie), silnie interdyscyplinarna i globalna. W laboratorium realizuje się duże, finansowane projekty badawcze, wykorzystuje technologie do produkcji metody badawczej oraz tworzy teorie naukowe na podstawie działań praktycznych. Dodatkowo laboratorium znosi podział hierarchiczny między kadrą a studentami, którzy razem pracują nad jednym projektem w jednym pomieszczeniu. Przykładami laboratoriów humanistycznych są: Stanford Literary Lab, metaLab na Uniwersytecie Harvarda, the Humanities Laboratories na

Ł. Afeltowicz Modele, artefakty, kolektywy..., s. 421-422.

60 G. Hiatt We need humanities labs, „Inside Higher Ed” 26.10.2005, https://www.insidehighered. com/views/2005/10/26/we-need-humanities-labs (10.03.2016). 
Duke University, Maker Lab na University of Victoria, Digital Humanities Lab na Yale University czy Laboratorium Cyfrowe Humanistyki Uniwersytetu Warszawskiego.

Humanistyka cyfrowa szczególnie realizuje model pracy laboratoryjnej, ponieważ jak wspomniałam, w jej ramach prowadzi się projekty, których nie da się wykonać w pojedynkę bez wsparcia finansowego i zaplecza technologicznego. Celem pracy humanisty staje się making things, a dopiero potem praktykowanie teorii (theory in practice).

\section{w*}

Latour w Science in Action stwierdza, że nie jesteśmy już proszeni, by wierzyć w tekst, który czytamy, ale by wierzyć „naszym własnym oczom”61. „Tekst” został zastąpiony przez wizualizację, symulację, mapping czy modelowanie danych. Transformacji humanistyki służy zmiana jej słownika zaczerpniętego z nauk ścisłych. Zapożyczanie pojęć ma siłę sprawczą - laboratoryjne praktyki nie są już metaforą badawczą, ale rzeczywistą strategią metodologiczną humanisty. W obliczu zwrotów w humanistyce, ekonomii i kryzysów, przeorganizowanie humanistyki staje się koniecznością, a nie wyborem. Nie oznacza to wcale utraty tożsamości humanistyki, bowiem to od nas zależy, co przechwycimy, co rozwiniemy, a co zaoferujemy innym naukom. Ostatecznie laboratoria mają stworzyć przede wszystkim obszar współpracy międzydziedzinowej i międzyinstytucjonalnej, wychodząc poza scientyczne założenia jego powstania w naukach ścisłych. Laboratorium wiąże się $\mathrm{z}$ wprowadzeniem nowego modelu realizacji badań, a nie z zanegowaniem dotychczasowych badań humanistycznych, określanych jako „tradycyjne”. W laboratorium humanista, "tradycyjny" $\mathrm{i}$,cyfrowy”, powinien usiąść wraz z programistą, technologiem czy designerem, by wspólnie dyskutować o problemach rozpatrywanych transdyscyplinarnie, jak np. o etyce technologii cyfrowych $^{62}$, mediach empatycznych, archiwach cyfrowych, kształtowaniu pamięci cyfrowej ${ }^{63}$, narzędziach cyfrowych dyskryminujących ze względu na

61 B. Latour Science in Action. How to Follow Scientists and Engineers through Society, Harvard University Press, Cambridge 1987, s. 66.

Przykładem są badania nad etyką samoprowadzącego się samochodu prowadzone m.in. w Media Lab na MIT oraz w Culture and Morality Lab na University of California, Irvine.

63 Zagadnienie pamięci cyfrowej wiąże się choćby z istotnym problemem usuwania danych cyfrowych. (J. Van Dijck Mediated Memories in the Digital Age, Stanford University Press, Stanford 
płeć czy o aplikacjach naruszających ludzką intymność. Pole badań humanistycznych obecnie wykracza daleko poza dotychczasowy obraz zakresu pracy humanistycznej. Wyjście „poza humanistykę” pozwoli wzmocnić humanistykę na nowo. Projektowanie kultury, społeczeństwa i współczesnego świata może odbyć się tylko w odpowiednich do tego warunkach - w warunkach laboratoryjnych.

\section{Abstract}

\section{Urszula Pawlicka}

UNIVERSITY OF WARMIA AND MAZURY IN OLSZTYN

The Humanities: A Workshop, a Centre, or a Laboratory?

The fact that laboratories are becoming increasingly popular in the humanities forces us to think about the field's structural transformation - its sources, meaning and consequences. Pawlicka examines how functional and methodological changes relate to the sites where research is undertaken. She proposes that throughout the history of the humanities, a change of site is always an institutional strategy and a response to the challenges of the time. The goal is, therefore, to examine the situation and the factors that motivated the creation of laboratories in the humanities, such as the remodelling of the university as a corporation, the crisis of the humanities, as well as the development of the digital humanities. Having looked at internal factors, Pawlicka analyses and compares three sites of the humanities: the workshop, the centre and the laboratory. A change of site, she concludes, signifies the construction of new structures and new hierarchies. Thus the creation of laboratories is presented as part of the tactical turn in the humanities.

\section{Keywords}

workshop, centre, laboratory, humanities, crisis of the humanities, tactical turn, digital humanities

2007; W.H.K. Chun Programmed Visions: Software and Memory, The MIT Press, Cambridge-London 2011; V. Mayer-Schönberger Delete: the Virtue of Forgetting in the Digital Age, Princeton University Press, Princeton 2011; A.S. Rumsey When We Are No More: How Digital Memory is Shaping Our Future, Bloomsbury Press, London 2016). 